\title{
Effects of deposition parameters on the structure and properties of ZrN, WN and ZrWN films
}

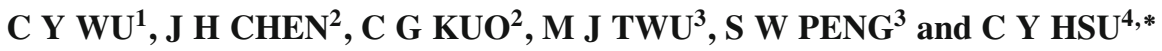 \\ ${ }^{1}$ Marine College, Beibu Gulf University, Qinzhou 535011, People's Republic of China \\ ${ }^{2}$ Department of Industrial Education, National Taiwan Normal University, Taipei 106, Taiwan \\ ${ }^{3}$ Department of Mechatronic Engineering, National Taiwan Normal University, Taipei 106, Taiwan \\ ${ }^{4}$ Department of Mechanical Engineering, Lunghwa University of Science and Technology, Taoyuan 33306, Taiwan \\ *Author for correspondence (cyhsu@ mail.lhu.edu.tw)
}

MS received 24 January 2018; accepted 31 March 2018; published online 7 February 2019

\begin{abstract}
This paper examines optimal settings for deposition parameters for transition metal nitride ( $\mathrm{ZrN}, \mathrm{WN}$ and ZrWN) thin films that are deposited on tungsten carbide tools and glass substrates using direct current (DC) reactive sputtering with pure $\mathrm{Zr}$ and $\mathrm{W}$ metal targets and Ar plasma and $\mathrm{N}_{2}$ reactive gases. Experiments using the grey-Taguchi method are conducted to study the effects of deposition parameters (substrate plasma etching time, $\mathrm{N}_{2} /\left(\mathrm{N}_{2}+\mathrm{Ar}\right.$ ) flow rate, deposition time and substrate temperature) on a film that is deposited on a cutting tool that is used for dry machining and on the films' mechanical properties. The substrates' surfaces are etched using oxygen plasma pretreatment. It is clear that the coated film is homogeneous, very compact and exhibits perfect adherence to the substrate. The results of grey relational analysis show for the dry turning AISI 304 stainless steel that the surface roughness is approximately $R_{\mathrm{a}}=0.70 \mu \mathrm{m}$ and that the flank wear is approximately $14.02 \mu \mathrm{m}$. The grey relational analysis shows that the period for which the substrate (tungsten carbide tool) is under plasma-etched pretreatment has the most significant effect on both the surface roughness and flank wear. The coated films are analysed using scanning electron microscopy (SEM), energy-dispersive spectroscopy (EDS), transmission electron microscopy (TEM), X-ray diffraction and a nano-indenter. The ternary nitride (ZrWN)-coated specimens exhibit better mechanical properties than binary nitride ( $\mathrm{ZrN}$ and $\mathrm{WN})$ specimens. The optimum $\mathrm{ZrWN}$ coating exhibits the greatest hardness $(H)$, elastic modulus $(E)$ and $H / E$ values.
\end{abstract}

Keywords. Transition metal nitride films; grey-Taguchi method; dry cutting; TEM.

\section{Introduction}

Solid ceramic thin films that are made of transition metal nitrides, such as $\mathrm{ZrWN}, \mathrm{CrWN}$, TiAlN and TiN, are used on cutting and forming tools for various industrial applications where the environment causes abrasive wear and as a diffusion barrier and protective layer [1]. The transition metal nitrides have a low coefficient of friction, a low wear rate, high mechanical hardness, high thermal and chemical stability and their use allows a longer operational life for a cutting tool [2]. Of these transition metal nitride films, ZrWN possesses the best properties as a protective coating for many applications [3]. Kim et al [4] reported that the structural and mechanical properties of films depend significantly on the $\mathrm{Zr}$ content and showed that the film hardness and the elastic modulus increase as $\mathrm{Zr}$ content increases. Dubey et al [5] reported that the structural and elemental composition of $\mathrm{ZrWN}$ films depend on the nitrogen partial pressure. ZrWN films exhibit great hardness ( $\sim 24 \mathrm{GPa})$ and toughness.

Typical hard coating films for cutting materials that are difficult to machine (such as stainless steel, titanium alloys and nickel-based alloys) are currently being coated using reactive magnetron sputtering. These coated tools have a longer life and produce a good finished surface, which has a low coefficient of friction, is highly tough and exhibits good adhesion [6]. Several deposition techniques are used to grow hard films. Co-reactive sputtering is suitable for hard films, because it is cheap and the deposition parameters can be controlled and it allows good uniformity in large components on an industrial scale [7]. Traditional experimental methods require a large number of experiments when the number of process parameters increases. The Taguchi method [8] increases the experimental efficiency and is extensively used in designing and improving product qualities in various industries. The mixed orthogonal table for the Taguchi quality design is used to derive important deposition factors. A statistical analysis of the signal-to-noise $(\mathrm{S} / \mathrm{N})$ ratio is followed by an analysis of variance (ANOVA) [9]. Senthilkumar et al [10] analysed machining characteristics, including flank wear, surface roughness and material removal rate, to optimize the deposition process using the grey relational grade and experiments that were designed using the Taguchi method. 
Table 1. Settings for factors and levels for co-sputtering deposition to form $\mathrm{ZrWN}$.

\begin{tabular}{|c|c|c|c|}
\hline \multirow{2}{*}{$\begin{array}{l}\text { Substrates } \\
\text { Metal target }\end{array}$} & \multicolumn{3}{|c|}{ Tungsten carbide tool P10 and glass } \\
\hline & \multicolumn{3}{|c|}{$\mathrm{W}$ and $\mathrm{Zr}(99.95 \%)$} \\
\hline Gas & \multicolumn{3}{|c|}{ Ar and $\mathrm{N}_{2}(99.95 \%)$} \\
\hline Base pressure & \multicolumn{3}{|c|}{$4.8 \times 10^{-6}$ Torr } \\
\hline Substrate-to-target distance & \multicolumn{3}{|l|}{$85 \mathrm{~mm}$} \\
\hline Substrate rotational speed & \multicolumn{3}{|l|}{$10 \mathrm{rpm}$} \\
\hline Working pressure & \multicolumn{3}{|c|}{$5.0 \times 10^{-3}$ Torr } \\
\hline W DC power & \multicolumn{3}{|c|}{$100 \mathrm{~W}$} \\
\hline Zr DC power & \multicolumn{3}{|l|}{$100 \mathrm{~W}$} \\
\hline \multicolumn{4}{|l|}{ Coated with $\mathrm{ZrN}, W N$ and $\mathrm{ZrWN}$} \\
\hline Control factor & Level 1 & Level 2 & Level 3 \\
\hline Substrate plasma etching time (min) & 5 & 10 & 15 \\
\hline $\mathrm{N}_{2} /\left(\mathrm{N}_{2}+\mathrm{Ar}\right)(\%)$ & 10 & 25 & 40 \\
\hline Deposition time (min) & 5 & 10 & 15 \\
\hline Substrate temperature $\left({ }^{\circ} \mathrm{C}\right)$ & Room & 100 & 200 \\
\hline \multicolumn{4}{|l|}{ Substrate plasma etching pretreatment } \\
\hline
\end{tabular}

Sarıkaya et al [11] used Taguchi grey analysis to optimize machining parameters using multiple response outputs for the turning of cobalt-based superalloys, which are difficult to machine.

In this study, ZrWN hard films were deposited onto tungsten carbide tool substrates using direct current (DC) reactive magnetron co-sputtering. The optimal coating parameters are obtained by analysing the results of various experimental permutations. In order to study the effects of the control factors (substrate plasma etching time, $\mathrm{N}_{2} /\left(\mathrm{N}_{2}+\mathrm{Ar}\right)$ flow rate, deposition time and substrate temperature) on the deposition of ZrWN hard films, four factors, each at three levels, are considered. An $\mathrm{L}_{9}\left(3^{4}\right.$, with four columns and nine rows) orthogonal array is used. Table 1 shows the factor and level settings for the deposition of ZrWN hard films. Turning operations are important machining processes for the production of various components that require machining operations. AISI 304 stainless steel is dry-turned using these coated tools. In this study, the effect of optimizing the deposition parameters for ZrWN hard films on the structure, surface roughness and flank wear during the dry machining process was studied. The mechanical properties of the ZrN, WN and ZrWN films, including the elastic modulus, the hardness and the elastic recovery, are measured using a nano-indentation system.

\section{Experimental}

The composite $\mathrm{ZrN}$, WN and $\mathrm{ZrWN}$ coatings were deposited onto tungsten carbide tools (P10, TNMG160404R-UM, Sumitomo) using a closed-field unbalanced DC magnetron cosputtering system (figure 1), with pure $\mathrm{Zr}$ and $\mathrm{W}$ metal targets (99.95\%, diameter: $76 \mathrm{~mm}$ ). A mixture of high purity
(99.95\%) Ar plasma and $\mathrm{N}_{2}$ reactive gases were used. The DC power for the $\mathrm{Zr}$ and $\mathrm{W}$ targets was maintained at $100 \mathrm{~W}$ for this study. The substrates (tungsten carbide tools and glass) were cleaned using a standard procedure that included a degreasing process and an acid treatment and were then cleaned by oxygen plasma etching for different periods, ranging from 5 to $15 \mathrm{~min}$ (table 1). Pre-sputtering was performed for $10 \mathrm{~min}$, in order to clean and equilibrate the target surface prior to deposition.

The tungsten carbide tools that were coated with $\mathrm{ZrN}$, $\mathrm{WN}$ and $\mathrm{ZrWN}$ were used in a low-cost conventional lathe (CH-400, KINWA Machine Tool Co. Ltd., Taiwan), to turn a cylindrical AISI 304 stainless-steel work piece (table 2). The typical chemical composition and the physical and thermal properties of AISI 304 are given in [12]. Taguchi grey analysis was used to study the effects of various co-sputtering factors, in order to produce a good surface finish and to decrease flank wear for the cutting tool. To ensure the reproducibility of the results, all tests were performed twice and the average values are presented.

In terms of the turning process, the average values for the machined surface roughness $\left(R_{\mathrm{a}}\right)$ were measured after each experiment. A profilometer (Suftest-402 Mitutoyo) was used for $R_{\mathrm{a}}$ measurements. A field-emission scanning electron microscope (FESEM, JEOL JSM $6500 \mathrm{~F}$ ) was used to observe the microstructures of the surface and cross-sections. The thickness of the coatings was determined directly from the cross-sectional microstructure. The nanostructure of the coatings was analysed using a transmission electron microscope (Philips Tecnai F20 G2 FEI-TEM). The films' structural properties were determined using X-ray diffraction (Rigaku-2000 X-ray Generator), using $\mathrm{CuK} \alpha$ radiation $(40 \mathrm{kV}, 30 \mathrm{~mA}$ and $\lambda=1.541 \AA$ ) with a grazing incidence 


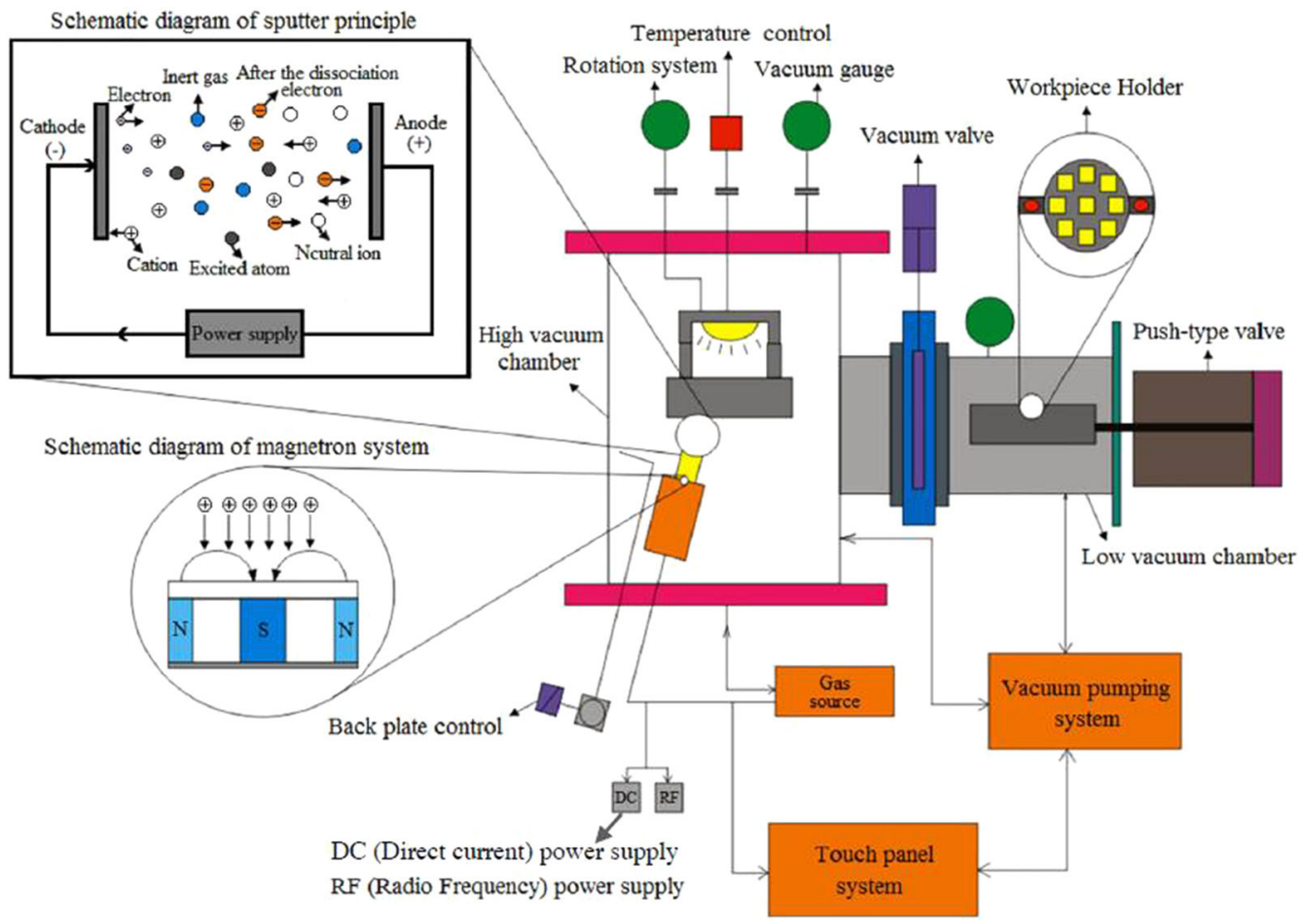

Figure 1. Schematic diagram of an unbalanced DC magnetron co-sputtering system.

Table 2. Dry turning parameters.

\begin{tabular}{lc}
\hline $\begin{array}{l}\text { Work-piece material } \\
\text { Cutting tool }\end{array}$ & $\begin{array}{c}\text { AISI 304 stainless steel, 45 mm diameter } \\
\text { With and without ZrWN-, WN- and } \\
\text { ZrN-coated }\end{array}$ \\
Cutting fluid & Dry cutting \\
Cutting length & $75 \mathrm{~mm}$ \\
Spindle speed & $1800 \mathrm{rpm}^{-1}$ \\
Feed rate & $0.9 \mathrm{~mm} \mathrm{rev}^{-1}$ \\
Depth of cut & $2 \mathrm{~mm}$ \\
\hline
\end{tabular}

angle of $2^{\circ}$. The values for the micro-hardness, the elastic modulus and the elastic recovery of the $\mathrm{ZrN}$, WN and $\mathrm{ZrWN}$ coatings were determined using a nano-indenter (ASMEC UNAT) at room temperature.

\section{Results and discussion}

By adjusting the experimental permutations, the effects of each deposition parameter were studied for the $\mathrm{ZrWN}$ film on an energy-dispersive spectrometer (EDS) compositional analysis, the surface morphology, micro-hardness, elastic modulus, elastic recovery and machining performance of a coated tool during dry turning. The tungsten carbide tool substrates were cleaned using a standard procedure that included a degreasing process and an acid treatment. They were then cleaned using oxygen plasma etching pretreatment, in order to increase the adhesive strength of the $\mathrm{ZrWN}$ coatings. The tungsten carbide tool substrate surfaces were etched for different periods (5, 10 and $15 \mathrm{~min}$ ), using a DC power of $200 \mathrm{~W}$ and oxygen plasma. The results are shown in figure 2. This figure shows that the surface roughness of the substrate increases as the etching time increases (from $R_{\mathrm{a}}=0.07$ to $0.67 \mu \mathrm{m}$ ). Modification of the surface of the substrates by bombarding with energetic plasma alters the surface morphology. The increase in surface roughness is in good agreement with the changes in the surface that are observed using SEM (figure 2) and with the increase in the common roughness as a result of the preferential sputtering of polycrystalline materials due to sputtering [13]. Figure 3 shows the cross-sectional SEM images for the coated $\mathrm{ZrWN}$ film. It is seen that the ZrWN film is homogeneous, very compact and that it exhibits perfect adherence to the substrate. No cracking or peel-off is observed after deposition. A ZrWN film with a thickness of 152-287 nm was deposited in this study.

Dry machining does not use a coolant because this is a pollutant and modern cutting processes seek to decrease environmental waste. Table 3 shows the experimental results for the dry turning of AISI 304 stainless steel with and without a $\mathrm{ZrWN}$ film coating and the corresponding $\mathrm{S} / \mathrm{N}$ ratios. After dry turning using a ZrWN-coated tool, the surface roughness and the flank wear are significantly reduced. All the coated tools have a much longer tool life than the uncoated tools. Table 4 lists the results for the ANOVA for the surface roughness and flank wear (corresponding to table 3 ). The substrate temperature $(P=32.56 \%)$ and the time for which 


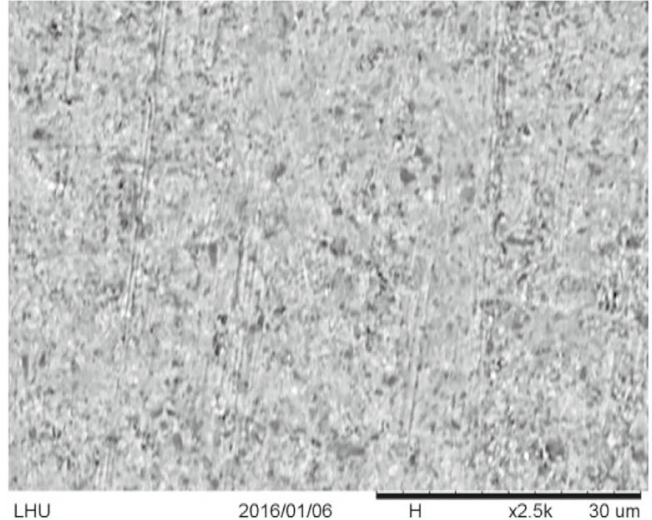

(a) $\mathrm{Ra}=0.07 \mu \mathrm{m}$

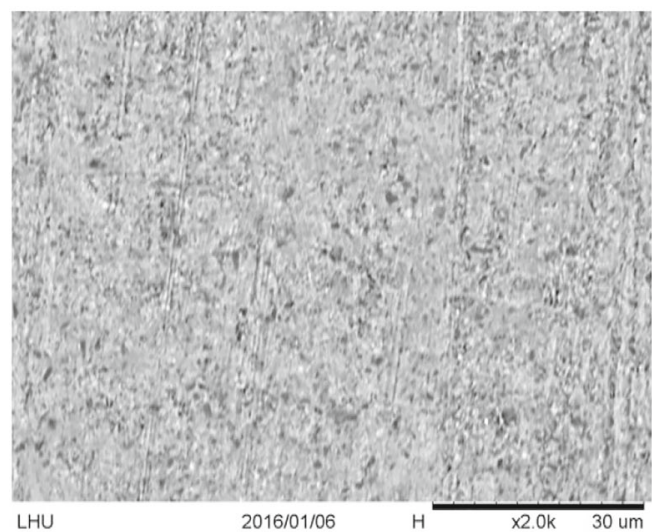

(c) $\mathrm{Ra}=0.49 \mu \mathrm{m}$

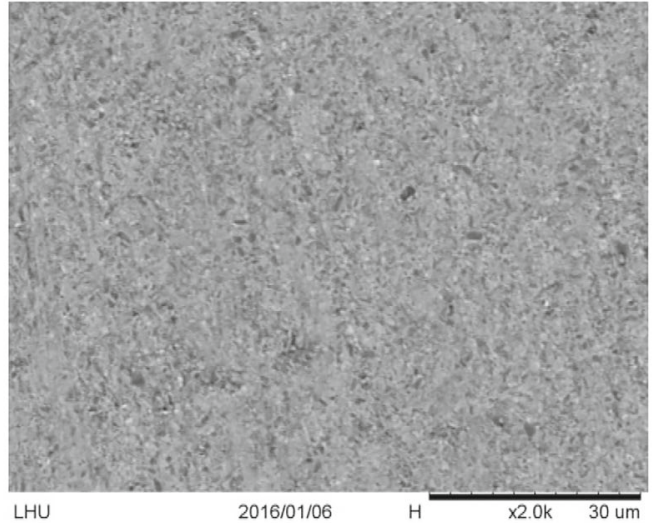

(b) $\mathrm{Ra}=0.36 \mu \mathrm{m}$

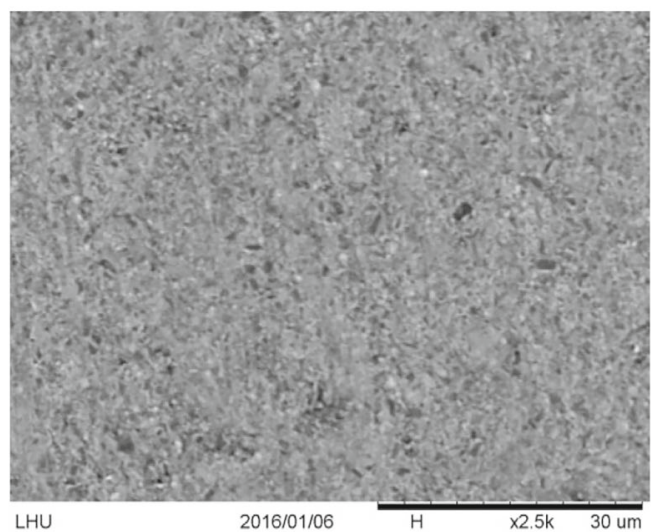

(d) $\mathrm{Ra}=0.67 \mu \mathrm{m}$

Figure 2. SEM morphology for tungsten carbide tool P10 substrates using a DC power of $200 \mathrm{~W}$ and oxygen plasma pretreatment for etching times of: (a) no etching, (b) $5 \mathrm{~min}$, (c) $10 \mathrm{~min}$ and (d) $15 \mathrm{~min}$.

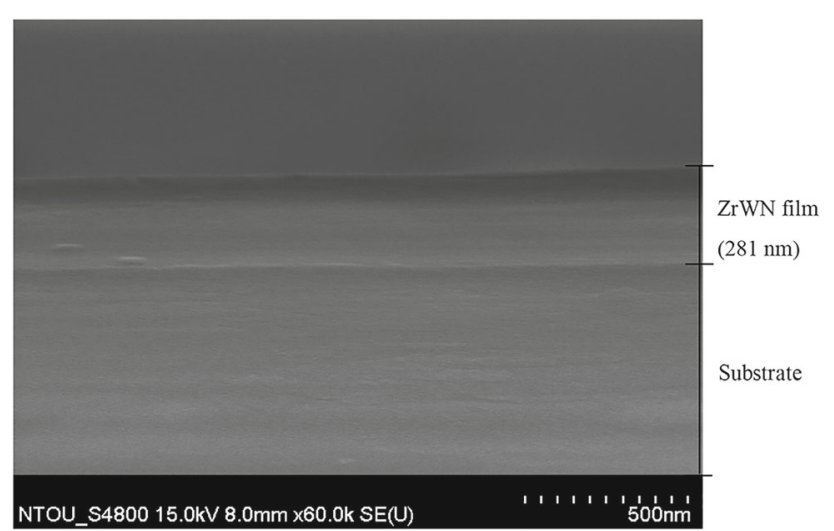

Figure 3. Cross-sectional SEM images for the $\mathrm{ZrWN}$ film coatings.

the substrate is plasma etched ( $P=29.00 \%)$ have the greatest effects on the surface roughness. The time for which the substrate is plasma etched is the most significant factor for flank wear, with an approximate contribution of 37.99\%, followed by deposition time, with an approximate contribution of $26.06 \%$.

\subsection{Optimal coating parameters for a ZrWN hard film}

Grey relational analysis is used to determine the complicated relationships between multiple performance characteristics. The grey relational coefficient is [14]

$$
\begin{aligned}
r & \left(x_{0}(k), x_{i}(k)\right) \\
= & \frac{\min _{i} \min _{k}\left|x_{0}(k)-x_{i}(k)\right|+\zeta \max _{i} \max _{k}\left|x_{0}(k)-x_{i}(k)\right|}{\left|x_{0}(k)-x_{i}(k)\right|+\zeta \max _{i} \max _{k}\left|x_{0}(k)-x_{i}(k)\right|}
\end{aligned}
$$

where $x_{i}(k)$ is the normalized value of the $k$ th performance characteristic in the $i$ th experiment and $\zeta$ is a distinguishing coefficient and $\zeta \in\lfloor 0,1\rfloor$. The value of $\zeta$ is adjusted according to the actual system requirements. The $\mathrm{ZrWN}$ hard film 
Table 3. Experimental results and the $\mathrm{S} / \mathrm{N}$ ratios for surface roughness and flank wear for a cutting tool that is coated with the $\mathrm{ZrWN}$ film and used for dry turning (experiments were run twice).

\begin{tabular}{|c|c|c|c|c|c|c|c|c|c|c|}
\hline \multirow[b]{2}{*}{ No. } & \multicolumn{4}{|c|}{ Factors } & \multicolumn{2}{|c|}{ Surface roughness $\left(R_{\mathrm{a}}, \mu \mathrm{m}\right)$} & \multirow[b]{2}{*}{$\mathrm{S} / \mathrm{N}(\mathrm{dB})$ lower is better } & \multicolumn{2}{|c|}{ Flank wear $(\mu \mathrm{m})$} & \multirow[b]{2}{*}{$\mathrm{S} / \mathrm{N}(\mathrm{dB})$ lower is better } \\
\hline & $A$ & $B$ & $C$ & $D$ & $s_{1}$ & $s_{2}$ & & $f_{1}$ & $f_{2}$ & \\
\hline 1 & 1 & 1 & 1 & 1 & 0.91 & 0.94 & 0.68 & 17.33 & 19.66 & -25.36 \\
\hline 2 & 1 & 2 & 2 & 2 & 0.87 & 0.82 & 1.46 & 26.22 & 26.47 & -28.41 \\
\hline 3 & 1 & 3 & 3 & 3 & 0.79 & 0.80 & 1.99 & 18.54 & 24.16 & -26.66 \\
\hline 4 & 2 & 1 & 2 & 3 & 0.73 & 0.74 & 2.67 & 15.86 & 21.82 & -25.61 \\
\hline 5 & 2 & 2 & 3 & 1 & 0.85 & 0.89 & 1.21 & 17.14 & 26.72 & -27.02 \\
\hline 6 & 2 & 3 & 1 & 2 & 0.95 & 1.01 & 0.17 & 17.67 & 24.63 & -26.62 \\
\hline 7 & 3 & 1 & 3 & 2 & 0.69 & 0.72 & 3.03 & 13.81 & 18.67 & -24.31 \\
\hline 8 & 3 & 2 & 1 & 3 & 0.79 & 0.71 & 2.49 & 13.42 & 15.43 & -23.20 \\
\hline 9 & 3 & 3 & 2 & 1 & 0.83 & 0.83 & 1.62 & 19.32 & 23.56 & -26.67 \\
\hline \multicolumn{5}{|c|}{ Uncoated tool } & 1.18 & 1.24 & & 38.37 & 36.78 & \\
\hline
\end{tabular}

Note: $A=$ substrate plasma etching time $(\mathrm{min}), B=\mathrm{N}_{2} /\left(\mathrm{N}_{2}+\mathrm{Ar}\right)$ ratio $(\%), C=$ deposition time $(\mathrm{min})$ and $D=$ substrate temperature $\left({ }^{\circ} \mathrm{C}\right)$.

Table 4. ANOVA results for surface roughness and flank wear, corresponding to table 3 .

\begin{tabular}{|c|c|c|c|c|c|c|c|}
\hline \multirow[b]{2}{*}{ Factors } & \multicolumn{3}{|c|}{$\mathrm{S} / \mathrm{N}$ ratio $(\mathrm{dB})$} & \multirow[b]{2}{*}{ Degree of freedom } & \multirow[b]{2}{*}{ Sum of squares } & \multirow[b]{2}{*}{ Variance } & \multirow[b]{2}{*}{ Contribution $(P, \%)$} \\
\hline & Level 1 & Level 2 & Level 3 & & & & \\
\hline \multicolumn{8}{|c|}{ Surface roughness } \\
\hline$A$ & 1.38 & 1.35 & 2.38 & 2 & 2.07 & 1.03 & 29.00 \\
\hline$B$ & 2.13 & 1.72 & 1.26 & 2 & 1.13 & 0.56 & 15.85 \\
\hline$C$ & 1.11 & 1.92 & 2.08 & 2 & 1.61 & 0.80 & 22.59 \\
\hline$D$ & 1.17 & 1.56 & 2.38 & 2 & 2.32 & 1.16 & 32.56 \\
\hline Total & & & & 8 & 7.13 & & 100 \\
\hline \multicolumn{8}{|c|}{ Flank wear } \\
\hline$A$ & -26.81 & -26.42 & -24.73 & 2 & 7.37 & 3.68 & 37.99 \\
\hline$B$ & -25.09 & -26.21 & -26.65 & 2 & 3.88 & 1.94 & 20.00 \\
\hline C & -25.06 & -26.90 & -25.00 & 2 & 5.05 & 2.53 & 26.06 \\
\hline$D$ & -26.35 & -26.45 & -25.16 & 2 & 3.09 & 1.55 & 15.95 \\
\hline Total & & & & 8 & 19.39 & & 100 \\
\hline
\end{tabular}

coating parameters are equally weighted for this study so $\zeta$ is 0.5 .

When the grey relational coefficient is derived, the average value of the grey relational coefficients is defined as the grey relational degree. This is defined as below [14]

$$
r\left(x_{0}, x_{i}\right)=\frac{1}{n} \sum_{k=1}^{n} r\left(r_{0}(k), x_{i}(k)\right)
$$

where $n$ is the number of performance characteristics.

In this study, the surface roughness and flank wear for the ZrWN-coated tools for dry turning AISI 304 are the multiple performance characteristics. These are converted into a single grey relational degree using equations (1 and 2 ). The grey relational grade for each experiment in the L9 orthogonal array is shown in table 5. Experiment no. 6 exhibits the highest grey relational grade, which demonstrates that the optimal set of process parameters $\left(A_{2} B_{3} C_{1} D_{2}\right)$
Table 5. Grey relational grade and its order in the optimization process.

\begin{tabular}{|c|c|c|c|c|c|c|}
\hline \multirow[b]{2}{*}{ No. } & \multicolumn{4}{|c|}{ Factors } & \multirow[b]{2}{*}{ Grey relational grade } & \multirow[b]{2}{*}{ Order } \\
\hline & $A$ & $B$ & $C$ & $D$ & & \\
\hline 1 & 1 & 1 & 1 & 1 & 0.489 & 6 \\
\hline 2 & 1 & 2 & 2 & 2 & 0.414 & 8 \\
\hline 3 & 1 & 3 & 3 & 3 & 0.534 & 4 \\
\hline 4 & 2 & 1 & 2 & 3 & 0.698 & 3 \\
\hline 5 & 2 & 2 & 3 & 1 & 0.449 & 7 \\
\hline 6 & 2 & 3 & 1 & 2 & 0.402 & 9 \\
\hline 7 & 3 & 1 & 3 & 2 & 0.883 & 1 \\
\hline 8 & 3 & 2 & 1 & 3 & 0.877 & 2 \\
\hline 9 & 3 & 3 & 2 & 1 & 0.492 & 5 \\
\hline
\end{tabular}

has the best performance characteristics from nine experiments. Figure 4 shows that the optimum conditions for good multiple performance characteristics for the $\mathrm{ZrWN}$ hard 


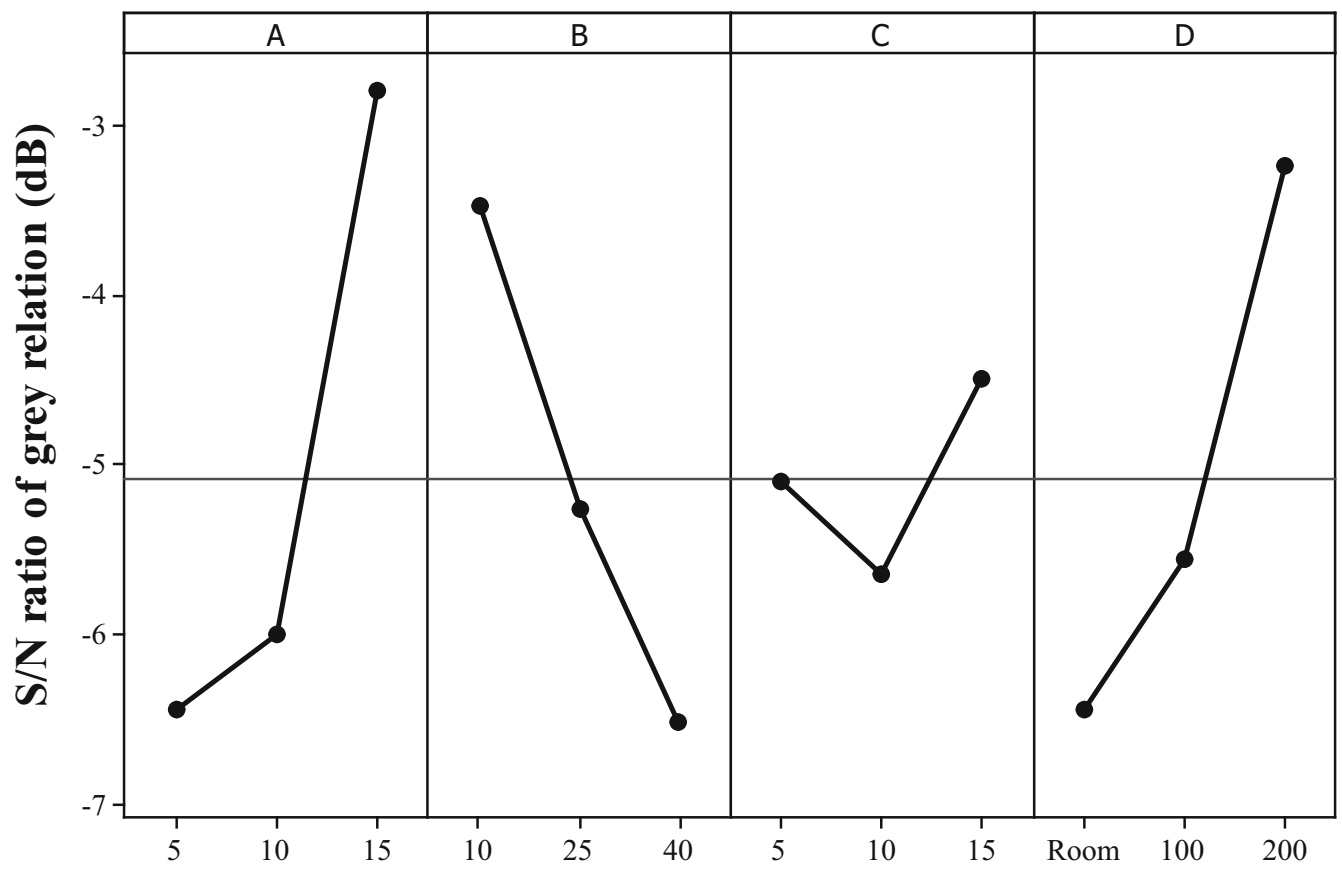

Figure 4. S/N graph for the grey relational grade.

Table 6. Results of the confirmation experiment for the multiple performance characteristics for the orthogonal array and the optimal predicted deposition parameters.

\begin{tabular}{lccc}
\hline & Orthogonal array & Grey theory prediction design & \\
& $A_{3} B_{1} C_{3} D_{2}$ & $A_{3} B_{1} C_{3} D_{3}$ & Improvement rate (\%) \\
\hline \multirow{4}{*}{ For a tool that is coated with $\mathrm{ZrWN}$ and used for dry turning AISI 304 } \\
Roughness $(\mu \mathrm{m})$ & 0.71 & 0.70 & 1.41 \\
Flank wear $(\mu \mathrm{m})$ & 16.24 & 14.02 & 13.67 \\
\hline
\end{tabular}

film coatings are produced by the combination, $A_{3} B_{1} C_{3} D_{3}$, which denotes a substrate plasma etching time of $15 \mathrm{~min}$, a $\mathrm{N}_{2} /\left(\mathrm{N}_{2}+\right.$ Ar) flow rate of $10 \%$, a deposition time of 15 min and a substrate temperature of $200^{\circ} \mathrm{C}$. The experimental results for the multiple performance characteristics for ZrWN hard films are shown in table 6. It is evident that the multiple performance characteristics for these film coatings are improved using the Taguchi grey method. A comparison of the grey theory deposition parameters with the orthogonal array parameters shows that, for the dry turning of AISI 304, the surface roughness is reduced slightly from 0.71 to $0.70 \mu \mathrm{m}$ and the flank wear decreases from 16.24 to $14.02 \mu \mathrm{m}$. Figure 5 shows the XRD diffraction patterns for the $\mathrm{ZrWN}$ film coatings in the $\mathrm{L}_{9}$ orthogonal array from nos. 1 to 9 , using grey theory prediction (optimal deposition parameters). ZrWN films exhibit a single face centred cubic (FCC) phase with the (111) and (200) crystallographic orientations of the grains. There is a preferred (111) orientation for these deposition conditions in which the strain energy is large and dominant. This is in agreement with the results of Dubey et al [5], who found that the lowest strain energy plane is (111) and the lowest surface energy plane is (200), which produce competitive grain growth (evolutionary selection rule).

The grey theory prediction shows that the intensity of the peaks becomes stronger, which denotes an improvement in the crystalline quality and the performance characteristics. The films were subjected to TEM analysis to confirm the phases. Figure 6 shows the bright-field TEM images and the selected area electron diffraction (SAED) patterns, which confirm that the FCC phase is present in the $\mathrm{ZrWN}$ films. Table 7 lists the EDS compositional analyses for the ZrWN film, which contains $\mathrm{Zr}, \mathrm{W}$ and $\mathrm{N}_{2}$ elements. It is seen that a $\mathrm{Zr}$ content of $\sim 28.54$ at $\%$, a W content of $\sim 48.19$ at $\%$ and a $\mathrm{N}_{2}$ content of $\sim 23.27$ at $\%$ produce good multiple performance characteristics for the $\mathrm{ZrWN}$ film coating. Figure 7 shows a comparison of the cutting surfaces of the machined work pieces (figure $7 \mathrm{a}, \mathrm{c}$ and e) and the flank wear for the tungsten carbide tool (figure 7b, d and f), using a cutter that has a ZrWN coating and one that does not. The cutting performance is improved when coated tools are used. It is significant 


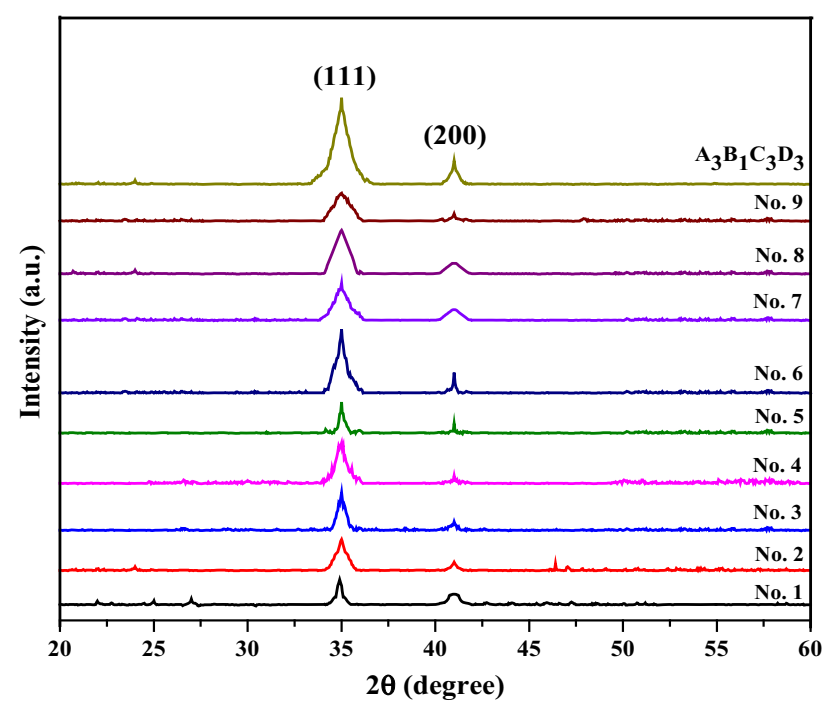

Figure 5. XRD patterns for the $\mathrm{ZrWN}$ films that are coated onto tungsten carbide tools for the L9 orthogonal array from nos. 1 to 9, using grey theory prediction design deposition parameters.

that the machined surface for the coated tool for which the film uses the $A_{3} B_{1} C_{3} D_{3}$ grey theory design deposition parameters and exhibits fewer surface defects, such as pockmarks and cracks (figure 7e). The tool flank wear reduces when a coated tool is used (figure 7f).

Table 8 lists the results for the ANOVA for the multiple performance characteristics for the $\mathrm{ZrWN}$-coated tools. Grey relational analysis shows that the duration for which the substrate (tungsten carbide tool P10) is plasma etched $(P=42.28 \%)$ is the most significant factor for both the surface roughness and the flank wear. The effect of the substrate plasma etching times was studied for durations of $12.5,15,17.5$ and $20 \mathrm{~min}$ and by fixing the other variables
Table 7. EDS images for a ZrWN film.

\begin{tabular}{|c|c|c|c|c|c|c|c|c|}
\hline \multirow[b]{2}{*}{ No. } & \multicolumn{4}{|c|}{ Factors } & \multicolumn{4}{|c|}{$\begin{array}{c}\text { Chemical composition, } \\
\text { atomic } \%\end{array}$} \\
\hline & $A$ & $B$ & $C$ & $D$ & $\mathrm{Zr}$ & $\mathrm{W}$ & $\mathrm{N}$ & Total \\
\hline 1 & 1 & 1 & 1 & 1 & 29.21 & 51.36 & 19.43 & 100 \\
\hline 2 & 1 & 2 & 2 & 2 & 21.55 & 56.27 & 22.18 & 100 \\
\hline 3 & 1 & 3 & 3 & 3 & 23.16 & 44.63 & 32.21 & 100 \\
\hline 4 & 2 & 1 & 2 & 3 & 29.61 & 52.35 & 18.04 & 100 \\
\hline 5 & 2 & 2 & 3 & 1 & 27.25 & 46.52 & 26.23 & 100 \\
\hline 6 & 2 & 3 & 1 & 2 & 28.03 & 40.61 & 31.36 & 100 \\
\hline 7 & 3 & 1 & 3 & 2 & 33.40 & 50.02 & 16.58 & 100 \\
\hline 8 & 3 & 2 & 1 & 3 & 27.16 & 47.42 & 25.42 & 100 \\
\hline 9 & 3 & 3 & 2 & 1 & 29.02 & 37.79 & 33.19 & 100 \\
\hline Optimal & 3 & 1 & 3 & 3 & 28.54 & 48.19 & 23.27 & 100 \\
\hline
\end{tabular}

in the grey theory prediction. Table 9 shows the surface roughness and flank wear for $\mathrm{ZrWN}$-coated tools that are plasma etched for different periods and used for the dry turning of AISI 304. The lowest values for surface roughness and flank wear were obtained when the substrate is plasma etched for $15 \mathrm{~min}$.

\subsection{Analysis of ZrN, WN and ZrWN films}

For comparison purposes, binary transition metal nitrides (ZrN group IV and WN group VI [5]) and ternary nitrides (ZrWN) were also coated. Figure 8 shows the XRD patterns of the $\mathrm{ZrN}$ and WN films, which exhibit a single FCC phase with (111), (200), (220) and (311) crystallographic orientations of the grains. This result is in agreement with the results of Maille et al [15]. Table 10 lists the experimental results for tools that are coated with $\mathrm{ZrN}$, WN and $\mathrm{ZrWN}$ using the optimal predicted deposition parameters $\left(A_{3} B_{1} C_{3} D_{3}\right)$ in

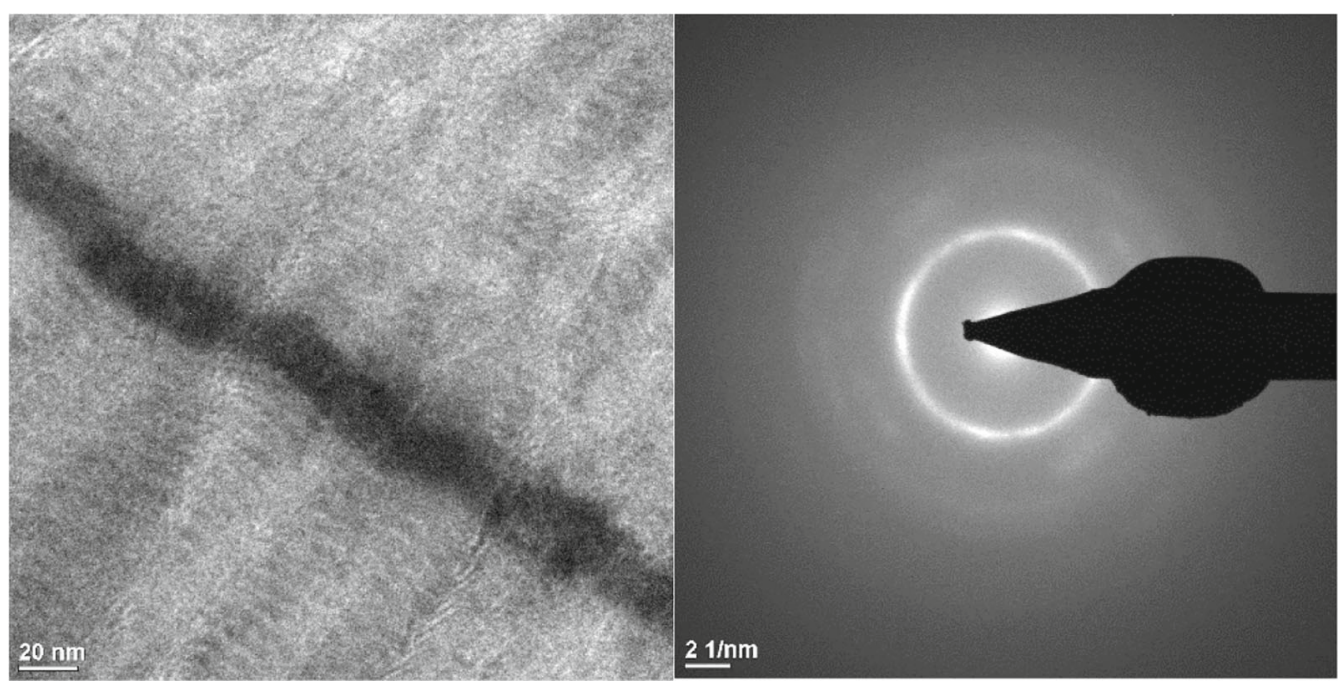

Figure 6. Topological bright-field images (left) and SAED patterns (right) showing a single FCC phase for $\mathrm{ZrWN}$ films. 

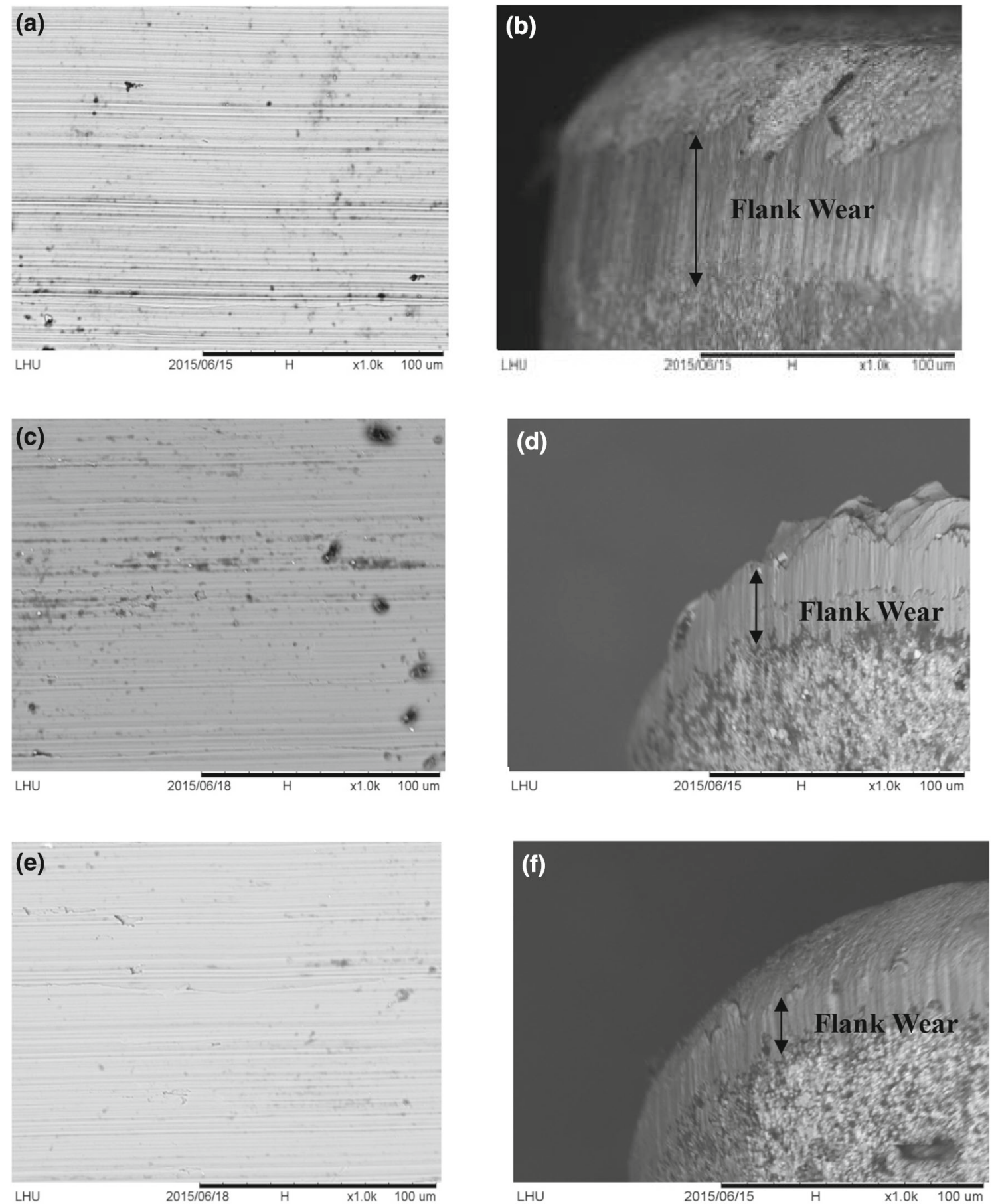

Figure 7. Comparison of the cutting surface of the machined work piece (a, $\mathbf{c}$ and $\mathbf{e})$ and the flank wear for the tungsten carbide tool (b, $\mathbf{d}$ and f) for: (a, b) an uncoated tungsten carbide tool, $(\mathbf{c}, \mathbf{d})$ a tool that is coated with $\mathrm{ZrWN}$ using the $A_{3} B_{1} C_{3} D_{2}$ orthogonal array deposition parameters and $(\mathbf{e}, \mathbf{f})$ a tool that is coated with $\mathrm{ZrWN}$ using the $A_{3} B_{1} C_{3} D_{3}$ grey theory design deposition parameters.

terms of the effect on the cutting tool after dry machining and on the films' mechanical properties. It is seen that the hardness of $\mathrm{ZrWN}$ is greater than that of $\mathrm{ZrN}$ and $\mathrm{WN}$. A similar result was published by Yao et al [16], who noted that the increase in the hardness of $\mathrm{ZrWN}$ is caused by the
Hall-Petch effect when there is refinement of the crystal size and the formation of a $\mathrm{WN}$ secondary phase in $\mathrm{ZrN}$ films. The experimental results show that the lowest values for surface roughness and flank wear are for $\mathrm{ZrWN}$-coated tools (table 10). 
Table 8. Results of the ANOVA for the grey relational grade for tools that are coated with ZrWN.

\begin{tabular}{lccccccc}
\hline & \multicolumn{3}{c}{ S/N ratio $(\mathrm{dB})$} & & & & \\
Fyctors & Level 1 & Level 2 & Level 3 & Degree of freedom & Sum of squares & Variance & Contribution $(P, \%)$ \\
\hline$A$ & -6.44 & -6.01 & -2.80 & 2 & 23.75 & 11.87 & 42.28 \\
$B$ & -3.47 & -5.25 & -6.52 & 2 & 14.05 & 7.03 & 25.01 \\
$C$ & -5.09 & -5.65 & -4.50 & 2 & 1.98 & 0.99 & 3.53 \\
$D$ & -6.45 & -5.55 & -3.24 & 2 & 16.39 & 8.20 & 29.18 \\
Total & & & & 8 & 56.17 & & 100 \\
\hline
\end{tabular}

Table 9. Effect of the duration for which the substrate (tungsten carbide tool P10) is plasma etched on surface roughness and flank wear for tools that are coated with ZrWN and used for dry turning AISI 304.

\begin{tabular}{|c|c|c|c|c|}
\hline Constant deposition parameters & $10 \%$ Deposition time temperature & $\mathrm{N}_{2} /\left(\mathrm{N}_{2}+\mathrm{Ar}\right)$ & Flow rate, $200^{\circ} \mathrm{C}$ & 15 Min, substrate \\
\hline Different plasma etching time (min) & 12.5 & 15 & 17.5 & 20 \\
\hline \multicolumn{5}{|c|}{ For a tool that is coated with ZrWN and used for dry turning AISI 304} \\
\hline Roughness $(\mu \mathrm{m})$ & 0.78 & 0.70 & 0.72 & 0.73 \\
\hline Flank wear $(\mu \mathrm{m})$ & 15.12 & 14.02 & 14.08 & 14.05 \\
\hline
\end{tabular}

(a)
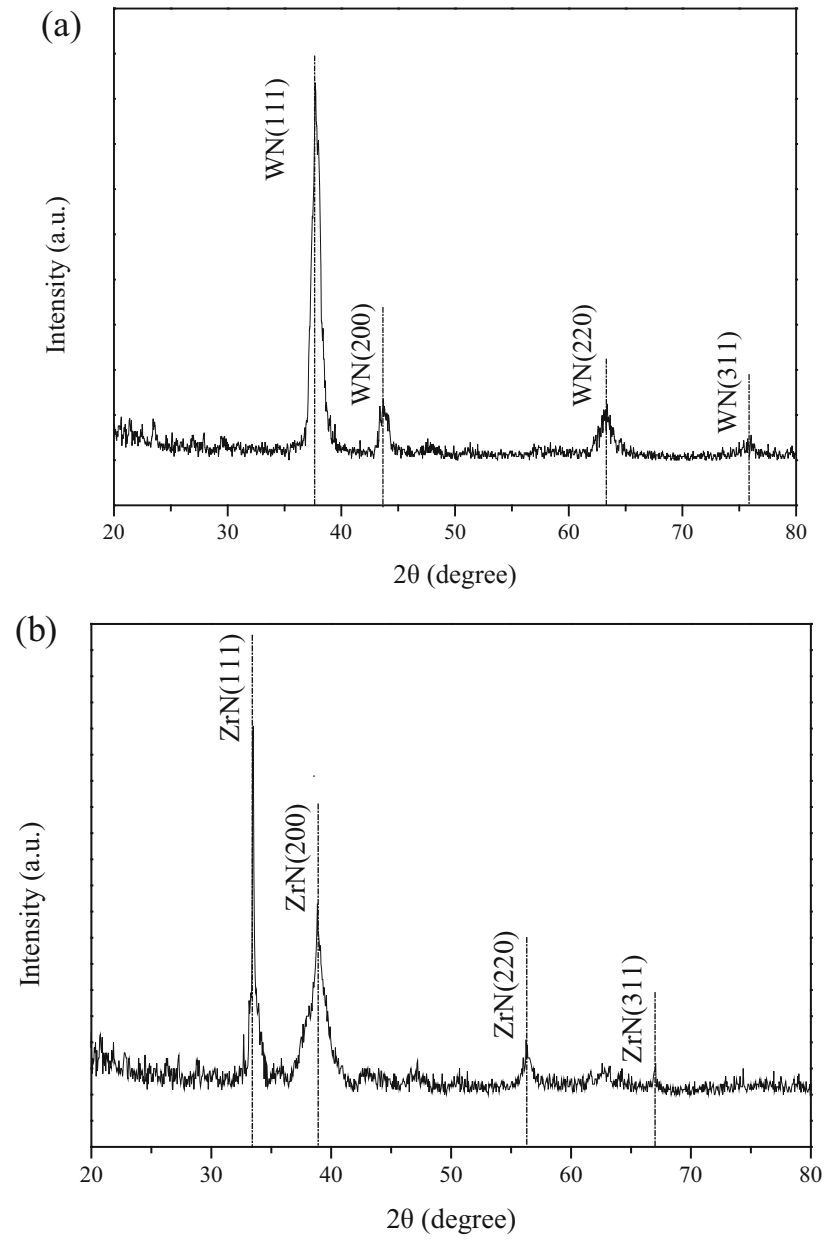

Figure 8. XRD patterns for: (a) $\mathrm{WN}$ and (b) $\mathrm{ZrN}$ film coatings.
Nano-indentation is used to measure the nano-mechanical properties of thin films. The hardness $(\mathrm{GPa})$, the elastic modulus (GPa) and the elastic recovery $(\%)$ are determined using the load-displacement curve and the film's wear resistance is determined using scratch tests [17]. The nano-mechanical properties of hard films are measured in terms of the depth to which the indenter penetrated at the maximum load, $h_{\max }$, the depth of the residual indent, $h_{\mathrm{r}}$ and the elastic recovery, $R_{\mathrm{e}}$ [18]. The $R_{\mathrm{e}}$ value denotes the ability to resist plastic deformation. The percentage of $R_{\mathrm{e}}$ is calculated in terms of $h_{\max }$ and $h_{\mathrm{r}}$ as follows [18]:

$$
\% R_{\mathrm{e}}=\frac{h_{\max }-h_{\mathrm{r}}}{h_{\max }} \times 100 \% \text {. }
$$

Figure 9 shows the typical nano-indentation loaddisplacement curves with the peak force loading of $5 \mathrm{mN}$. All of the curves show consecutive loading and unloading processes. There are three different nanostructures for $\mathrm{ZrN}$ $\left(h_{\max }=188.3 \mathrm{~nm}, h_{\mathrm{r}}=94.75 \mathrm{~nm}, \% R_{\mathrm{e}}=49 \%\right), \mathrm{WN}$ $\left(h_{\max }=133.2 \mathrm{~nm}, h_{\mathrm{r}}=49.59 \mathrm{~nm}, \% R_{\mathrm{e}}=62 \%\right)$ and $\mathrm{ZrWN}$ $\left(h_{\max }=118.8 \mathrm{~nm}, h_{\mathrm{r}}=37.14 \mathrm{~nm}, \% R_{\mathrm{e}}=68 \%\right)$. An irregularity in the curve is associated with a pop-in event (figure 9). This occurs because there are dislocations in the film's structure. The pop-in event is much smaller than the film thickness and only exists in films that are nano-crystalline [19]. Fan et al [20] reported that complex factors produce a stochastic pop-in event for different indentation loads.

For comparison, the values for the hardness $(H)$, the elastic modulus $(E), H / E$ and the elastic recovery for these hard films ( $\mathrm{ZrN}, \mathrm{WN}$ and $\mathrm{ZrWN})$ are summarized in table 10. The experimental results clearly show that specimens that are coated with ternary nitride $(\mathrm{ZrWN})$ exhibit better mechanical 
Table 10. Comparison of the experimental results for cutting tools that are coated with $\mathrm{ZrN}, \mathrm{WN}$ and $\mathrm{ZrWN}$ using the optimal predicted deposition parameters $\left(A_{3} B_{1} C_{3} D_{3}\right)$ and used for dry machining and the films' mechanical properties.

\begin{tabular}{lccc}
\hline & ZrWN & $\mathrm{WN}$ & $\mathrm{ZrN}$ \\
\hline For tools that are coated with $\mathrm{ZrWN}, \mathrm{WN}$ and $\mathrm{ZrN}$ and used for dry & turning AISI 304 \\
Roughness $(\mu \mathrm{m})$ & 0.70 & 1.03 & 1.18 \\
Flank wear $(\mu \mathrm{m})$ & 14.02 & 18.05 & 21.06 \\
Mechanical properties of the & $\mathrm{ZrWN}$, WN and $Z r N$ film coatings & \\
Hardness, $H(\mathrm{GPa})$ & 24.18 & 14.65 & 6.67 \\
Elastic modulus, $E(\mathrm{GPa})$ & 134.26 & 129.7 & 81.8 \\
Elastic recovery $\left(\% R_{\mathrm{e}}\right)$ & 68 & 62 & 49 \\
$H / E$ ratio & 0.18 & 0.11 & 0.08 \\
\hline
\end{tabular}

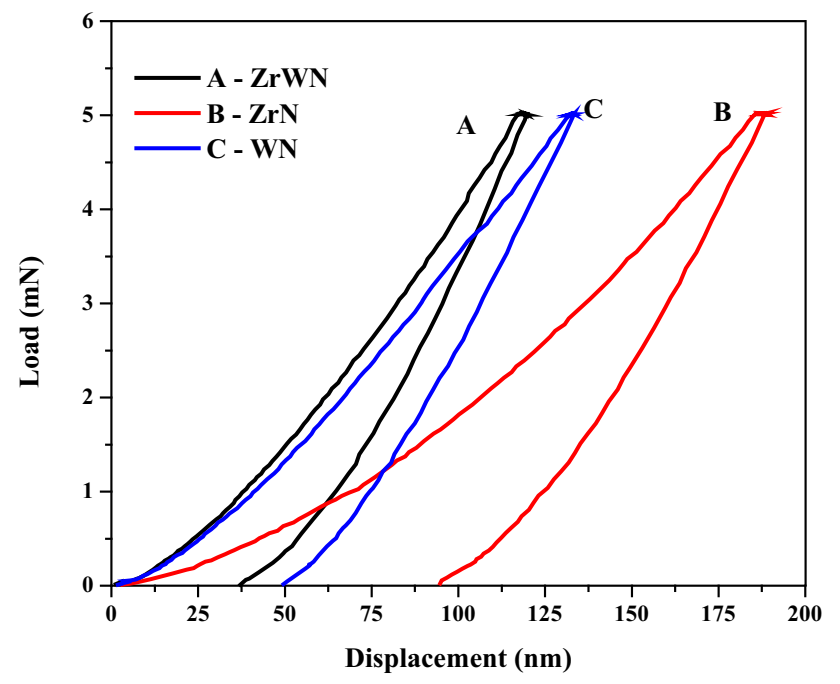

Figure 9. Representative nano-indentation load-displacement curves for tools that are coated with $\mathrm{ZrN}$, WN and $\mathrm{ZrWN}$ : the peak force occurs at a loading of $5 \mathrm{mN}$.

properties than those that are coated with binary nitrides ( $\mathrm{ZrN}$ and $\mathrm{WN}$ ). The optimum $\mathrm{ZrWN}$ coating has the highest values for hardness, elastic modulus and $H / E$.

\section{Conclusions}

In this paper, the effects of transition metal nitride ( $\mathrm{ZrN}, \mathrm{WN}$ and $\mathrm{ZrWN}$ ) films that are deposited by DC reactive magnetron sputtering on dry turning performance and mechanical properties were studied. The surface roughness and the flank wear for the $\mathrm{ZrWN}$-coated tools that are used to dry turn AISI 304 have the multiple performance characteristics. An $\mathrm{L}_{9}\left(3^{4}\right)$ orthogonal array and a grey-Taguchi method are used. The ANOVA results for the multiple performance characteristics for the tools that are coated with $\mathrm{ZrWN}$ show that the duration for which the substrate (tungsten carbide tool P10) is plasma etched has a significant effect, as determined by grey relational analysis. A comparison of the experimental results clearly shows that specimens that are coated with ZrWN give a better dry turning performance and have better mechanical properties than specimens that are coated with $\mathrm{ZrN}$ and $\mathrm{WN}$. The specimens that are coated with $\mathrm{ZrWN}$ have a high hardness value (24.18 GPa), a high elastic modulus $(134.26 \mathrm{GPa})$, a high elastic recovery $(68 \%)$ and a higher $H / E$ ratio.

\section{Acknowledgements}

The authors gratefully acknowledge the support of the Ministry of Science and Technology of the Republic of China, through Grant No. MOST 105-2221-E-262-005.

\section{References}

[1] Subramanian B, Prabakaran K and Jayachandran M 2012 Bull. Mater. Sci. 35505

[2] Hernandez-Torres J, Garcia-Gonzalez L, Zamora-Peredo L, Hernandez-Quiroz T, Sauceda-Carvajal A, Garcia-Ramirez P J et al 2012 Bull. Mater. Sci. 35733

[3] Dubey P, Dave V, Srivastava S, Singh D and Chandra R 2013 Surf. Coat. Technol. 237205

[4] Kim G S, Kim B S, Lee S Y and Hahn J H 2005 Surf. Coat. Technol. 2001669

[5] Dubey P, Arya V, Srivastava S, Singh D and Chandra R 2013 Surf. Coat. Technol. 236182

[6] Barshilia H C and Rajam K S 2003 Bull. Mater. Sci. 26233

[7] Addepalli S and Suda U 2016 Bull. Mater. Sci. 39789

[8] Jayabal S and Natarajan U 2011 Bull. Mater. Sci. 341563

[9] Gupta A, Singh H and Walia R S 2016 Bull. Mater. Sci. 39 1223

[10] Senthilkumar N, Tamizharasan T and Anandakrishnan V 2014 Measurement $\mathbf{5 8} 520$

[11] Sarıkaya M and Güllü A 2015 J. Clean Prod. 91347

[12] Rodriguez P, Khatak H S and Gnanamoorthy J B 1994 Bull. Mater. Sci. 17685 
[13] Gassner M, Schalk N, Sartory B, Pohler M, Czettl C and Mitterer C 2017 Int. J. Refract. Met. Hard Mater. 69 234

[14] Hu C C, Lu T W, Chou C Y, Wang J T, Huang H H and Hsu C Y 2014 Bull. Mater. Sci. 371275

[15] Maille L, Aubert P, Sant C and Garnier P 2004 Surf. Coat. Technol. 180-181 483

[16] Yao S H, Su Y L, Kao W H and Cheng K W 2006 Surf. Coat. Technol. 2012520
[17] Yilmaz F, Uzun O, Kolemen U, Kilicaslan M F, Basman N, Ergen S et al 2013 Bull. Mater. Sci. 361139

[18] Barshilia H C and Rajam K S 2004 Bull. Mater. Sci. 27 35

[19] Cabibbo M, Clemente N, Mehtedi M E, Hamouda A H, Musharavati F, Santecchia E et al 2015 Surf. Coat. Technol. 275155

[20] Fan X, Nose K, Diao D and Yoshida T 2013 Appl. Surf. Sci. 273816 